\title{
O INHANDUVÁ (PROSOPIS AFFINIS SPRENG.) NO RIO GRANDE DO SUL. 2 - OCORRÊNCIA NATURAL NA REGIÃO DO JARAU, QUARAÍ ${ }^{1}$
}

\author{
FABIANO DA SILVA ALVES ${ }^{2}$ JOSÉ NEWTON CARDOSO MARCHIORI ${ }^{3}$
}

\begin{abstract}
RESUMO
A distribuição geográfica do inhanduvá (Prosopis affinis Spreng., Fabaceae) no Rio Grande do Sul é presentemente estendida ao município de Quaraí, devido à comprovação de sua ocorrência natural em lente de solos arenosos próxima à encosta sul dos cerros do Jarau.

Palavras-chave: Prosopis affinis, Fitogeografia, Quaraí, Rio Grande do Sul.
\end{abstract}

\section{SUMMARY}

[Prosopis affinis Spreng. in Rio Grande do Sul state, Brazil. 2 - Natural occurrence in the region of Jarau Mountains, municipality of Quarai].

The geographic distribution of Prosopis affinis Spreng. (Fabaceae) in Rio Grande do Sul state (Brazil) is presently extended to the municipality of Quarai, due its natural occurrence on a sandy soil lens, close to southern slopes of Jarau Mountains.

Key words: Prosopis affinis, Phytogeography, municipality of Quarai, Rio Grande do Sul state, Brazil.

\section{INTRODUÇÃO}

Tema ainda não definitivamente esclarecido, a distribuição geográfica do inhanduvá (Prosopis affinis Spreng.) apresenta duas vertentes distintas na literatura botânica sul-riograndense, havendo autores que limitam sua ocorrência natural ao município de Barra do Quaraí e outros que indicam uma área mais ampla para a espécie, no oeste do Estado.

Entre os primeiros, Galvani (2003) afirma, nas "Considerações Finais" de sua tese de doutorado ${ }^{4}$, que a área do Parque Estadual do Espinilho constitui "o único ambiente de ocorrência de Prosopis affinis Griseb. e Prosopis nigra (Gris.) Hieron. no estado do Rio Grande

1 Recebido em 27-6-2010 e aceito para publicação em 28-8-2010.

2 Biólogo, MSc, doutorando do Programa de PósGraduação em Engenharia Florestal - UFSM. Professor da Universidade da Região da Campanha - URCAMP (Alegrete, RS).

3 Engenheiro Florestal, Dr. Professor Titular do Departamento de Ciências Florestais, UFSM. Bolsista de Produtividade em Pesquisa ( $\mathrm{CNPq}$ - Brasil). do Sul e no Brasil"5 . Na seqüência, o autor chama atenção para a necessidade de maiores pesquisas sobre a origem geológica da "porção sudoeste" do Estado, com vistas ao "esclarecimento da origem dessa singularidade" vegetacional.

Na corrente dos autores que postulam uma área mais ampla, incluem-se: Veloso \& GóesFilho (1982), Marchiori et al. (1983) e Marchiori (2004).

De acordo com Veloso \& Góes-Filho (1982), o inhanduvá limita-se a solos aluviais próximos ao rio Uruguai, de Barra do Quaraí até Uruguaiana $^{6}$.

Marchiori et al. (1983) estendem a ocorrência da espécie a "pontos isolados da Campanha do Sudoeste, notadamente ao longo da bacia do rio Ibicuî"?

${ }^{4}$ GALVANI, F.R. Vegetação e aspectos ecológicos do Parque Estadual do Espinilho, Barra do Quaraí, RS. Porto Alegre: Universidade Federal do Rio Grande do Sul, 2003.132f. Tese de Doutorado (Programa de PósGraduação em Botânica).

5 GALVANI, 2003. Op. cit., p. 87.

6 VELOSO, H.B.; GÓES-FILHO, L. Fitogeografia brasileira - Classificação fisionômico-ecológica da vegetação neotropical. Salvador: Projeto RADAMBRASIL, 1982. 80 p. (Boletim Técnico, Ser. Vegetação, v. 1). 
Marchiori (2004), por sua vez, assinala a presença do inhanduvá em alguns pontos da bacia do Ibicuí, inclusive no "município de São Vicente do Sul, sempre associado a depósitos aluviais" 8 .

No presente trabalho, segundo de uma série dedicada à distribuição geográfica de Prosopis affinis no Rio Grande do Sul, confirma-se a ocorrência natural da espécie em lente de solos arenosos próxima à encosta sul dos cerros do Jarau, no município de Quaraí, com o reforço de documentos históricos do primeiro quartel do século XX. Antes do exame destes registros convém examinar-se, todavia, o referencial fitogeográfico de Balduíno Rambo, colhido de sua visita à região em janeiro de 1941.

\section{APONTAMENTOS DE RAMBO}

Eminente botânico e fitogeógrafo, Balduíno Rambo deixou-nos, em "A Fisionomia do Rio Grande do Sul - Ensaio de Monografia Natural", um relato fundamental sobre a vegetação e paisagens da Campanha do Sudoeste, por ele visitada no ano precedente à edição definitiva deste verdadeiro clássico da literatura sulina ${ }^{9}$. $\mathrm{Na}$ referida obra, o nome inhanduvá aparece, pela primeira vez, ainda no texto relativo ao município de Quaraí, ao descrever uma viagem entre esta cidade e Uruguaiana:

"Na descida para o Quaraí Mirim, o meláfiro chega a formar verdadeiras abas na orla das coxilhas, com miríades de ágatas e pequenas drusas de quartzo, entre as quais rasteja a flora mais pobre

7 MARCHIORI, J.N.C.; LONGHI, S.J.; GALVÃO, L. O gênero Prosopis L. (Leguminosae Mimosoideae) no Rio Grande do Sul. Ciência e Natura, Santa Maria, n. 5, 1983. p. 173.

8 MARCHIORI, J.N.C. Fitogeografia do Rio Grande do Sul. Campos sulinos. Porto Alegre: EST, 2004. p. 63.

9 Antes da edição definitiva (1942), o autor publicara um opúsculo com o mesmo nome (A Fisionomia do Rio Grande), seguido pelo sub-título "Viagens de Estudo" (RAMBO, P.B., 1938). Resta informar que esta pequena obra não inclui referências à região da Campanha. que se possa imaginar. No campo das encostas, aparece pela primeira vez em escala apreciável o parque espinilho. Constituído, na essência pelo nhanduvaí, não lhe faltam o branquilho, a sombra-de-touro e a cina-cina". ${ }^{10}$

O exame superficial deste fragmento induz o leitor a pensar que o autor refere a ocorrência de Prosopis affinis Spreng. em campos de rochas vulcânicas ${ }^{11}$ próximos ao Arroio QuaraíMirim, bem como a existência, na região, de uma vegetação singular, por ele descrita - e posteriormente consagrada na literatura botânica sul-rio-grandense -, como "Parque Espinilho". Decorrente de confusão com o nome das árvores, nenhum dos pontos salientados resiste a exame criterioso, bastando uma leitura integral do capítulo dedicado à "Campanha do Sudoeste" para lograr-se o esclarecimento definitivo destas questões, que foram abordadas por Marchiori \& Alves em artigo precedente ${ }^{12}$.

O problema reside, basicamente, nas designações populares de Vachellia caven e Prosopis affinis $^{13}$ utilizadas por Rambo: nhanduvaí e algarrobo, respectivamente. $\mathrm{O}$ termo "espinilho", atribuído popularmente à Vachellia caven, foi reservado pelo autor para designar distintas vegetações com estrutura de parque -

${ }^{10}$ RAMBO, P.B. A fisionomia do Rio Grande do Sul. Ensaio de monografia natural. Porto Alegre: Of. Graf. da Imprensa Oficial, 1942. p. 115.

${ }^{11}$ Meláfiro, segundo Balduíno Rambo.

${ }^{12}$ Marchiori, J.N.C.; ALVES, F. da S. O inhanduvá (Prosopis affinis Spreng.) no Rio Grande do Sul. 1 Embasamento fitogeográfico e pendências terminológicas. Balduinia, Santa Maria, n. 24, p. 1-11, 2010.

${ }^{13}$ Na primeira edição de "A fisionomia do Rio Grande do Sul: Ensaio de monografia natural", o autor dá a esta espécie o nome de Prosopis juliflora (RAMBO, 1942. Op. cit., p. 104), corrigindo a identidade da mesma para Prosopis algarobilla na edição seguinte (RAMBO, 1956. p. 130). O primeiro destes binômios corresponde a uma espécie da América tropical (BURKART, 1978), cultivada em muitas partes do mundo, inclusive no nordeste brasileiro, mas exótica na bacia do Prata. Prosopis algarobilla, por sua vez, foi reduzido, com o tempo, à sinonímia de Prosopis affinis. 
e não apenas para a associação de Prosopis affinis e Vachellia caven dos arredores de Barra do Quaraí -, como esclarece, de modo inequívoco, o fragmento anteriormente transcrito. De fato: Balduíno Rambo também chama de "Parque Espinilho" à vegetação por ele encontrada na orla da mata ciliar do Arroio Quaraí-Mirim, a qual é marcada fisionômica e estruturalmente por indivíduos de Vachellia caven. Elemento típico de formações sedimentares, o verdadeiro inhanduvá (Prosopis affinis) não costuma habitar solos rasos oriundos de rochas vulcânicas (meláfiro, segundo Rambo), como os encontrados nos arredores do Quaraí-Mirim.

Se o texto acima analisado não faz referência ao inhanduvá propriamente dito (Prosopis affinis), cabe informar que o autor realizou uma coleta desta espécie em outra viagem à região: trata-se da exsicata 26.354 , conservada no Herbário PACA ${ }^{14}$. De acordo com a etiqueta ${ }^{15}$, reproduzida em artigo póstumo ${ }^{16}$, o referido material, com frutos imaturos, foi colhido em janeiro de 1945 na "Fazenda do Jarau", interior do município de Quaraí, da mesma população que motiva o presente trabalho.

\section{O INHANDUVÁ EM QUARAÍ}

Em novembro de 2009, por ocasião de coletas botânicas entre os Arroios Quaraí-Mirim e Garupá, na região do famoso Cerro do Jarau, foram inicialmente encontrados alguns indivíduos isolados de Prosopis affinis (Figura 1) em uma área sedimentar de aproximadamente $5,5 \mathrm{~km}$ de diâmetro, isolada por solos rasos oriundos de rochas vulcânicas, típicos do Planalto da Campanha. Visita posterior, na mesma área, re-

\footnotetext{
${ }^{14}$ Herbário Anchieta, da UNISINOS, São Leopoldo, RS.

${ }^{15}$ PACA 26354. Leg. Mimosoideae. Prosopis algarobilla Gris. var. ñandubay (Lor. ap. Gris.) Hassl. RS - Fazenda do Jarau, p. Quaraí. In campestribus siccis. 1945. fl. fr. semievoluto. Leg. B. Rambo SJ. Det. Emrich-Rambo. Sicher, 11.8.1954.

${ }^{16}$ RAMBO, B. Leguminosae Riograndenses. Pesquisas, Botânica, n. 23, 1966, p. 46.
}

velou a existência de um verdadeiro "parque de inhanduvá" (Figura 2) à margem direita da sanga de mesmo nome, próximo ao centro da referida lente sedimentar $\left(30^{\circ} 12^{\prime} 16^{\prime \prime} \mathrm{S}, 56^{\circ} 32^{\prime} 27^{\prime \prime} \mathrm{W}\right.$, $116 \mathrm{~m}$ de altitude).

Formado por dezenas de velhos inhanduvás, com escassas regenerações e uns poucos espinilhos (Vachellia caven), chama atenção, no estrato herbáceo do parque, a ausência do capim-caninha (Andropogon lateralis Nees), em vivo contraste com o verificado nos campos ao redor, dominados por esta gramínea (Figura 2C). Resta salientar a presença da tuna (Cereus hildmannianus K. Schum.) e da arumbeva-deflores-alaranjadas (Opuntia elata Salm Dyck), elementos igualmente presentes no parque de inhanduvá de Barra do Quaraí. Comparado a este, todavia, não se encontram na vegetação presentemente descrita: o algarrobo (Prosopis nigra (Griseb.) Hieron.), o quebracho (Aspidosperma quebrachoblanco Schltdl.), a cina-cina (Parkinsonia aculeata L.), a taleira (Celtis ehrenbergiana (Klotzsch) Liebm.) e Tillandsia ixioides Griseb., entre outros elementos característicos. Cabe registrar, entretanto, que a cina-cina é elemento frequente na orla da mata ciliar do Quaraí-Mirim, que a taleira não é rara nos campos da região e que Tillandsia duratii Visiani ocorre tanto em inhanduvás como em outras espécies arbóreas, além de blocos rochosos no Cerro do Jarau.

A área em questão, integrante da "Fazenda Jarau Velho", pertence, atualmente, a descendentes do Dr. João Carlos Olimpio Giudice, que foi aluno de Balduíno Rambo no Colégio Anchieta (Porto Alegre) e hospedou o cientista gaúcho em suas férias de verão, nos anos de 1941 e 1945.

Cabe observar que foi somente nesta segunda visita, posterior à edição original de "A Fisionomia do Rio Grande do Sul: Ensaio de monografia natural", que Balduíno Rambo coletou o material de inhanduvá comentado no capitulo precedente, motivo pelo qual o nome "algarrobo" não se encontra entre as plantas de 


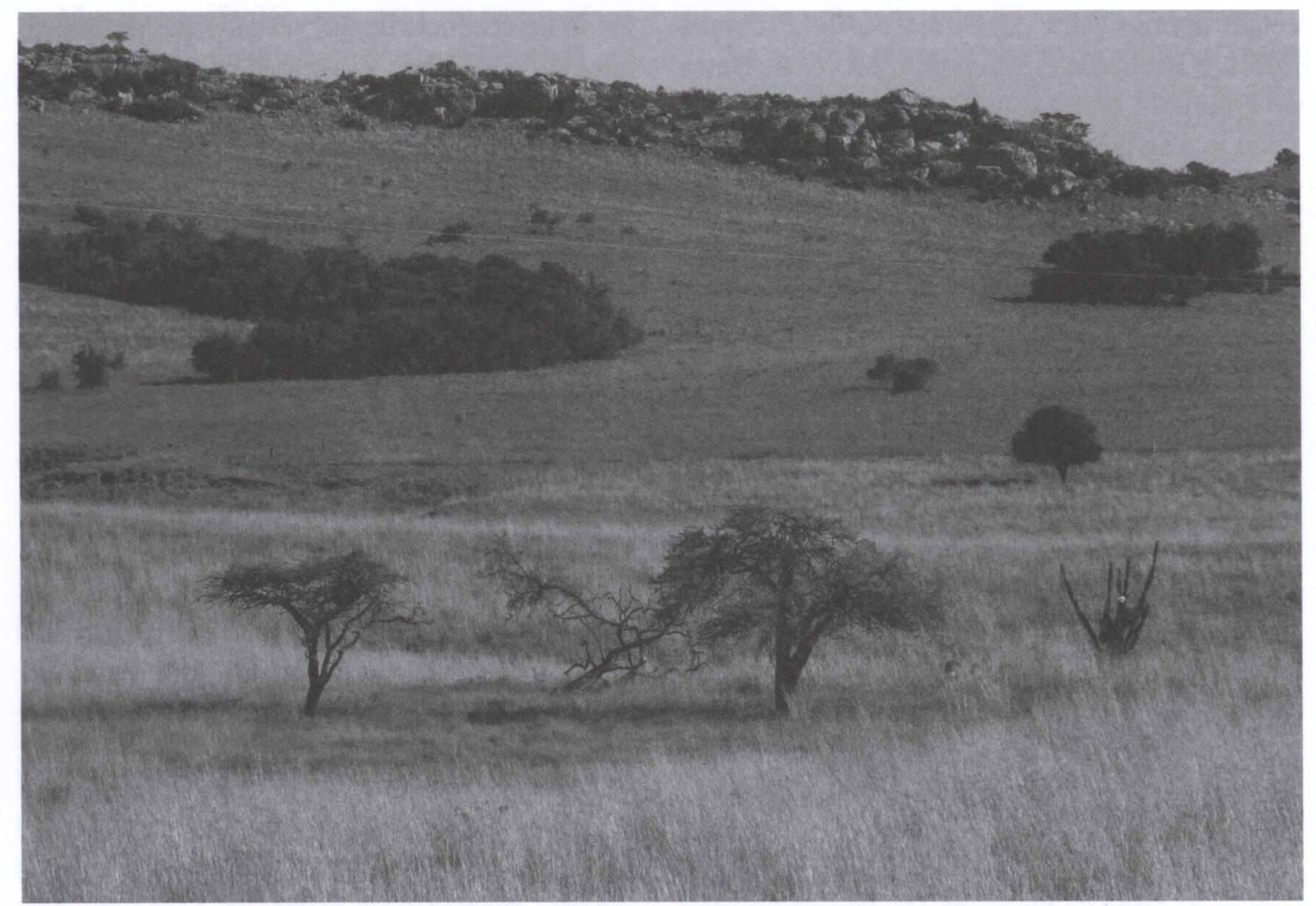

FIGURA 1 - Árvores isoladas de Inhanduvá, em campo arenoso ao sul dos cerros do Jarau.

Quaraí, citadas pelo autor. Resta informar que o grande botânico gaúcho refere-se, invariavelmente, a Prosopis algarobilla (atual Prosopis affinis) pelo nome comum de "algarrobo", termo largamente utilizado na Argentina para outras espécies do mesmo gênero botânico.

$\mathrm{O}$ nome do referido curso d'água consta em diversos mapas, inclusive na carta topográfica "Sanga Nanduvá", na escala 1:25.000, editada em 1988 (DSG - Ministério do Exército) ${ }^{17}$, que serviu de base para a confecção da Figura 3.

Por sua antiguidade, o nome da sanga serve como prova adicional, reforçando a interpretação do inhanduvá como espécie nativa na região. Sobre este ponto, o Major Souza Docca ${ }^{18}$,

${ }^{17}$ Termo utilizado na Carta Topográfica Militar - Folha SH.21-Z-A-I-2-SE (MI-2976/2-SE) do Ministério do Exército Brasileiro. Diretoria de Serviço Geográfico. Edição de 1988.

${ }^{18}$ Historiador e militar do Exército Brasileiro (chegou ao incluiu nota esclarecedora em artigo de 1925, publicado na Revista do Instituto Histórico e Geográfico do Rio Grande do Sul:

"Nhanduvahy - c. nhandu-uva-y, o rio das fructas da avestruz. Sanga tributária do Quarahy Mirim, no $1^{\circ}$ districto do mun. de Quarahy; nasce ao S. dos cerros de Jarau; seu curso é de 9 klms". ${ }^{19}$

Em documento manuscrito ainda mais antigo (1903), o Coronel Francisco Flores da $\mathrm{Cu}-$ nha ${ }^{20}$, que foi intendente de Quaraí no período

posto de General), Emílio Fernandes de Souza Docca nasceu em São Borja (16-7-1884) e faleceu no Rio de Janeiro (21-5-1945). Pertenceu ao Instituto Histórico e Geográfico do Rio Grande do Sul e à Academia RioGrandense de Letras (segunda fase).

${ }^{19}$ DOCCA, M. S. Vocabulos indigenas na Geographia riograndense. Revista do Instituto Historico e Geographico do Rio Grande do Sul, Porto Alegre, v. 5, n. 1,2, p. 52, 1925. (separata).

${ }^{20}$ Irmão mais velho de José Antônio Flores da Cunha, que 

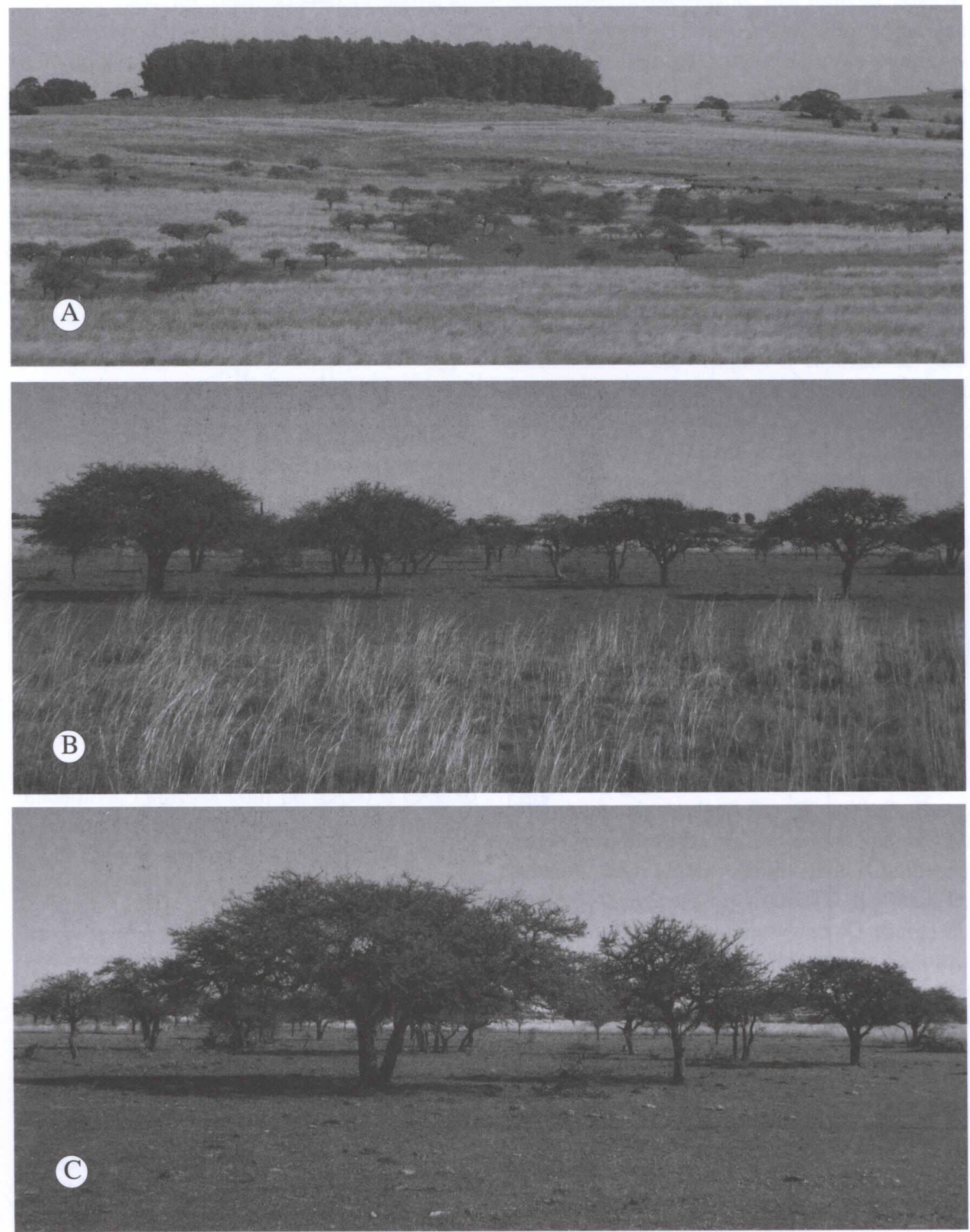

FIGURA 2 - Três aspectos do Parque de Inhanduvá. A - Vista parcial do parque de inhanduvá, em primeiro plano, junto à sanga de mesmo nome. B, C - Indivíduos velhos de inhanduvá; notar a ausência do capim-caninha (Andropogon lateralis) à sombra das árvores. 


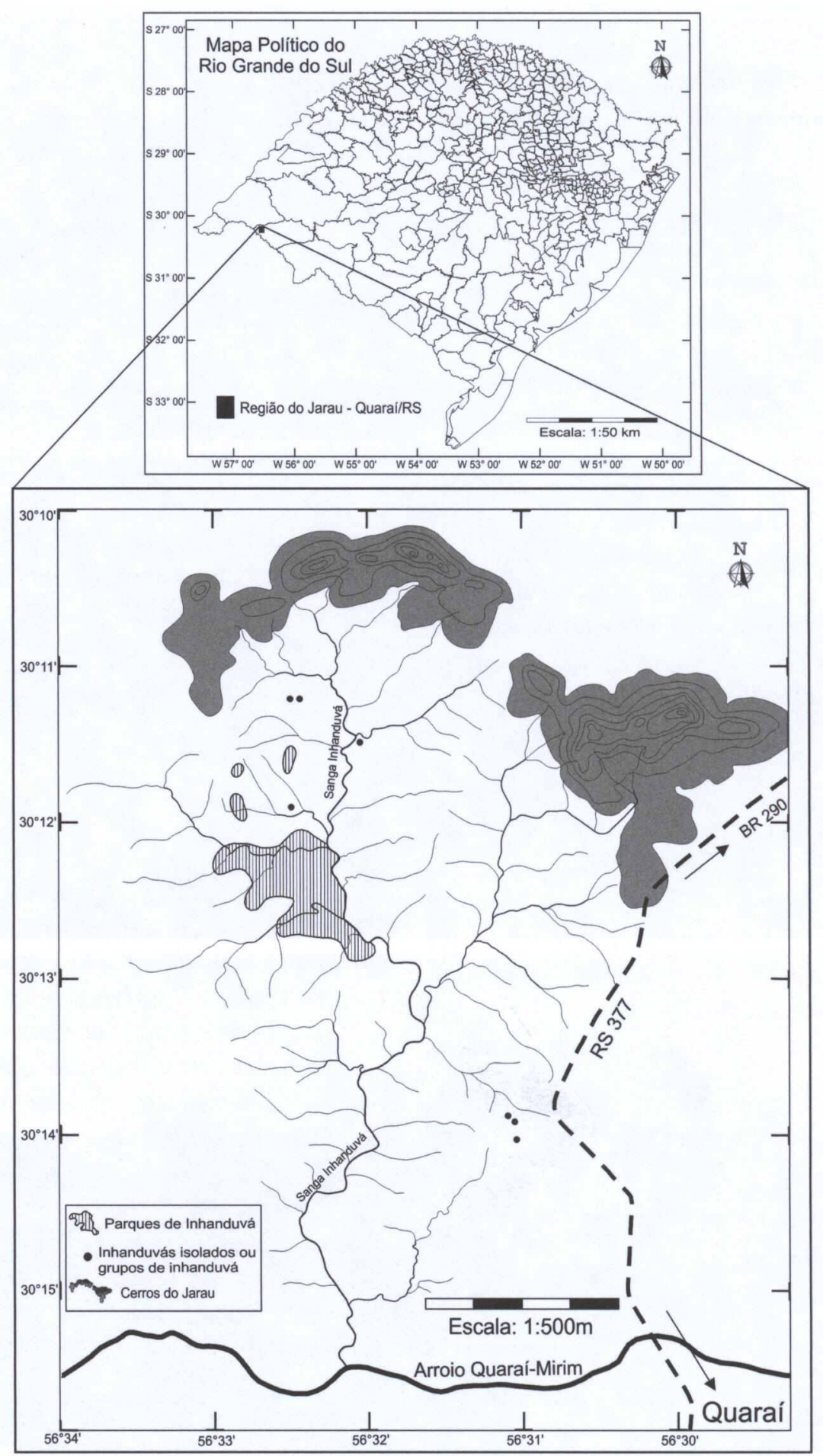

FIGURA 3 - Mapa de localização do Parque de Inhanduvá e indivíduos isolados desta espécie, ao sul dos cerros do Jarau, Quaraí - RS. 
de 1901 - 1904, registra a ocorrência natural do inhanduvá no município, ao responder o quesito "Noticias sobre os minereos, flora e fauna locaes", solicitado pelo Dr. Rivadávia da $\mathrm{Cu}-$ nha Corrêa $\mathrm{a}^{21}$ :

"A fauna é pobre e nenhuma especie della é digna de nota por não sahir do vulgar, bem como a flora, de que não se destaca nenhum especimen de valor. Existe algum inhanduvá entre costas do Quarahy e cerros de Jaráo em forte vertente que tira o nome da existência nella daquella madeira". ${ }^{22}$

Madeira bem conhecida e valorizada pelo homem do campo, por sua longa durabilidade natural, o inhanduvá é a única árvore lembrada neste antigo documento, que comprova, irrefutavelmente, a interpretação da espécie como integrante da flora autóctone de Quaraí. Neste caso, a hipótese antrópica pode ser descartada, tanto pela ausência de registro documental neste sentido, como pelo consensual pouco apreço dos antigos gaúchos no tocante ao cultivo de árvores nativas.

A respeito do texto do intendente, vale ressaltar que sua pobreza informativa, limitada ao inhanduvá, expressa com perfeição o escasso valor madeireiro da flora regional. No município de Quaraí, em verdade, são poucas as espécies e os indivíduos de interesse econômico en-

foi intendente de Uruguaiana e um dos lideres governistas das revoluções de 1923 e 1930.

${ }^{21}$ Bacharel em Direito (São Paulo, 1887) e eminente propagandista da Abolição e da República, Rivadávia da Cunha Corrêa nasceu em Livramento (9-7-1886) e faleceu em Petrópolis, Rio de Janeiro (9-2-1920). Além de intendente de Quaraí, foi Deputado Federal pelo Rio Grande do Sul (1895-1910), Ministro do Interior e Justiça na presidência Hermes da Fonseca (1910-1913), Ministro interino da Fazenda (1913), Prefeito do Distrito Federal (1914-1916) e Senador pelo Rio Grande do Sul (1916).

${ }^{22}$ CUNHA, F.F. da. Apontamentos historicos e informações geraes sobre o municipio de Quarahy compilados em 1903 pelo Intendente Cel. Francisco Flores da Cunha. In: CHEGUHEM, S.S. Quaraí Histórico. Quaraí: [s.n.], 1991. v. 2. p. 34. contrados em suas matas, que reúnem, basicamente: o sarandi (Pouteria salicifolia (Spreng.) Radlk.), o branquilho (Sebastiania commersoniana (Baill.) L.B. Smith \& Downs), o amarilho (Sebastiania schottiana (Müll. Arg.) Müll. Arg.), o salso-crioulo (Salix humboldtiana Willd.), o sucará (Gleditsia amorphoides (Griseb.) Taub.), o aguaí (Chrysophllum marginatum (Hook. \& Arn.) Radlk.), o pau-leiteiro (Sebastiania brasiliensis Spreng.), o chalchal (Allophylus edulis (A. St.-Hil., Cambess. \& A. Juss.) Radlk.), a aroeira-brava (Lithraea molleoides (Vell.) Engl.), o esporão-de-galo (Celtis iguanaea (Jacq.) Sarg.), o vacum (Allophylus guaraniticus (A. St.-Hil.) Radlk.), o veludinho (Guettarda uruguensis Cham. \& Schltdl.), os marmeleiros (Ruprechtia salicifolia (Cham. \& Schltdl.) C.A. Mey; Ruprechtia laxiflora Meisn.), os camboatás (Cupania vernalis Cambess.; Matayba elaeagnoides Radlk.), o topete-de-cardeal (Calliandra tweediei Benth.), bem como algumas capororocas (Myrsine lorentziana (Mez) Arechav., Myrsine laetevirens (Mez) Arechav.), canelas (Nectandra megapotamica (Spreng.) $\mathrm{Mez}$, Nectandra angustifolia (Schrad.) Nees, Ocotea acutifolia (Nees) Mez) e Mirtáceas (Blepharocalyx salicifolius (Kunth) O. Berg, Eugenia uniflora L., Myrcia selloi (Spreng.) N. Silveira, Myrcianthes cisplatensis (Cambess.) O. Berg, Myrcianthes gigantea (D. Legrand) D. Legrand, Myrcianthes pungens (O. Berg) D. Legrand, Myrrhinium atropurpureum Schott).

Limitadas a estreita faixa marginal nos principais rios e arroios, tais matas não incluem madeiras de valor econômico, com exceção de alguns indivíduos de angico-vermelho (Parapiptadenia rigida (Benth.) Brenan), guajuvira (Cordia americana (L.) Gottschling \& J.E.Mill.) e açoita-cavalo (Luehea divaricata Mart. \& Zucc.), provável motivo da não inclusão destas espécies no texto do Intendente.

A respeito do inhanduvá, cabe informar que a área de ocorrência natural presentemente descrita dista cerca de $100 \mathrm{~km}$ a leste do "Parque 


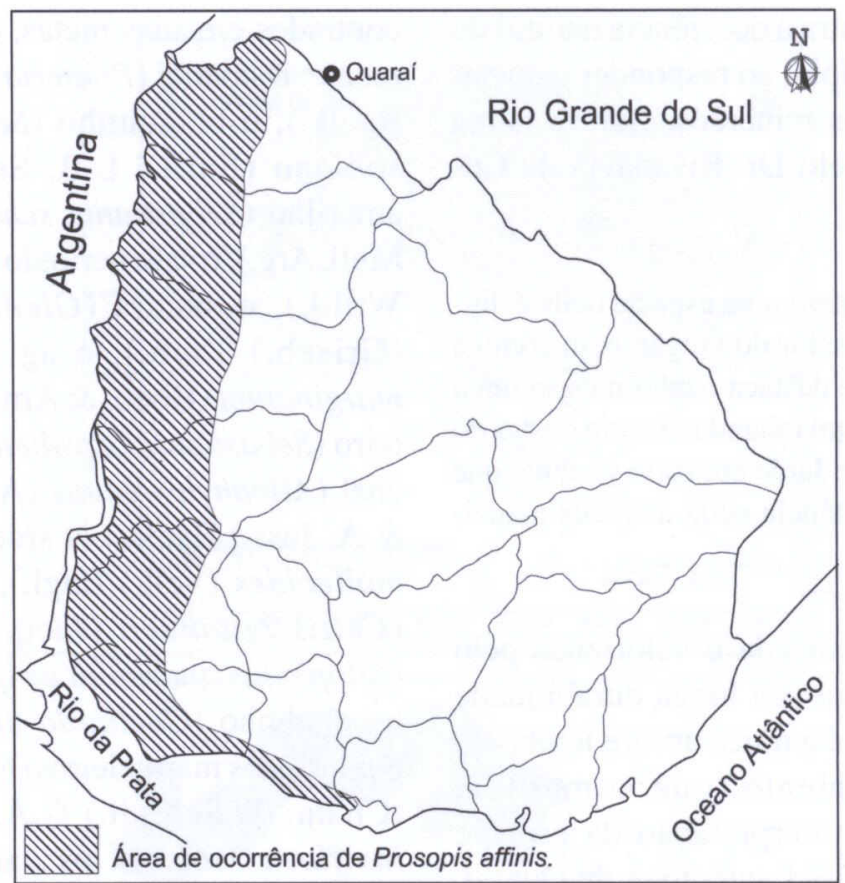

FIGURA 4 - Distribuição geográfica do Inhanduvá no Uruguai, segundo Brussa \& Grela (2007).

Estadual do Espinilho", em Barra do Quaraí. Espécie típica de formações sedimentares, caso do Chaco argentino, a disjunção entre estas duas populações explica-se, fundamentalmente, pela predominância de Neossolos Regolíticos ${ }^{23}$ oriundos de rochas vulcânicas em todo o Planalto da Campanha compreendido entre ambas.

No Uruguai, a distribuição geográfica da espécie corresponde a uma faixa paralela ao rio Uruguai, motivo pelo qual Brussa \& Grela (2007) referem-se ao inhanduvá como elemento típico dos "bosques de planícies del oeste". Sobre este ponto, Izaguirre \& Beyhaut (2003) informam que a espécie habita solos pedregosos, pradarias planas bem evoluídas e não erodidas, bem como bosques ribeirinhos.

No mapa fornecido pelos referidos autores (Figura 4) pode-se ver que na bacia do rio Quaraí a espécie se encontra até as proximidades de

${ }^{23}$ STRECK, E.V.; KÄMPF, N.; DALMOLIN, R.S.D.; KLAMT, E.; NASCIMENTO, P.C. do; SCHNEIDER, P.; GIASSON, E.; PINTO, L.F.S. Solos do Rio Grande do Sul. Porto Alegre: EMATER/RS - ASCAR, 2008. $222 \mathrm{p}$.
Artigas, cidade fronteira a Quaraí, sinalizando a rota imigratória seguida pela espécie, a leste do rio Uruguai.

\section{CONCLUSÕES}

Com base em documentos históricos, no exame da vegetação e em características litopedológicas, pode-se concluir que:

- Prosopis affinis Spreng. ocorre naturalmente no município de Quaraí, em formação sedimentar drenada pela Sanga do Inhanduvá, ao sul dos cerros do Jarau.

- A distribuição geográfica do inhanduvá no Rio Grande do Sul, por conseguinte, não se restringe ao município de Barra do Quaraí e, muito menos, aos limites do Parque Estadual do Espinilho, como afirmado por Galvani (2003).

\section{REFERÊNCIAS BIBLIOGRÁFICAS}

BRUSSA SANTANDER, C.A.; GRELA GONZÁLEZ, I.A. Flora arbórea del Uruguay. Con énfasis en las especies de Rivera y Tacuarembó. Montevideo: COFUSA, 2007. 542 p. 
BURKART, A. Leguminosas. In: DIMITRI, M.J. Enciclopedia argentina de agricultura y jardineria. Buenos Aires: Editorial ACME, 1978. v. 2.651 p.

CUNHA, F.F. da. Apontamentos historicos e informações geraes sobre o municipio de Quarahy compilados em 1903 pelo Intendente Cel. Francisco Flores da Cunha. In: CHEGUHEM, S.S. Quaraí Histórico. Quaraí: [s.n.], 1991. v. 2.229 p.

DOCCA, M.S. Vocabulos indigenas na Geographia riograndense. Revista do Instituto Historico e Geographico do Rio Grande do Sul, Porto Alegre, v. 5, n. 1,2, 1925. 168 p. (separata).

GALVANI, F.R. Vegetação e aspectos ecológicos do Parque Estadual do Espinilho, Barra do Quaraí, RS. Porto Alegre: Universidade Federal do Rio Grande do Sul, 2003. 132f. Tese de Doutorado (Programa de Pós-Graduação em Botânica).

IZAGUIRRE, P.; BEYHAUT, R. Las Leguminosas en Uruguay. Montevideo: Editorial Hemisferio Sur, 2003. 291 p.

MARCHIORI, J.N.C. Fitogeografia do Rio Grande do Sul. Campos sulinos. Porto Alegre: EST, 2004. $110 \mathrm{p}$.

MARCHIORI, J.N.C.; ALVES, F. da S. O inhanduvá (Prosopis affinis Spreng.) no Rio Grande do Sul.
1 - Embasamento fitogeográfico e pendências terminológicas. Balduinia, Santa Maria, n. 24, p. 1-11, 2010.

MARCHIORI, J.N.C.; LONGHI, S.J.; GALVÃO, L. O gênero Prosopis L. (Leguminosae Mimosoideae) no Rio Grande do Sul. Ciência e Natura, Santa Maria, n. 5, p. 171-177, 1983.

RAMBO, B. A fisionomia do Rio Grande. Viagens de estudo. Porto Alegre: Typografia do Centro, 1938. 54 p.

RAMBO, B. A fisionomia do Rio Grande do Sul. Ensaio de monografia natural. Porto Alegre: Of. Graf. da Imprensa Oficial, 1942. 360 p.

RAMBO, B. A fisionomia do Rio Grande do Sul. Ensaio de monografia natural. Porto Alegre: Livraria Selbach, 1956. 456 p.

RAMBO, B. Leguminosae riograndenses. Pesquisas, Botânica, n. 23, p. 1-166, 1966.

STRECK, E.V.; KÄMPF, N.; DALMOLIN, R.S.D.; KLAMT, E.; NASCIMENTO, P.C. do; SCHNEIDER, P.; GIASSON, E.; PINTO, L.F.S. Solos do Rio Grande do Sul. Porto Alegre: EMATER/RS - ASCAR, 2008. 222 p.

VELOSO, H.P.; GÓES-FILHO, L. Fitogeografia brasileira. Classificação fisionômico-ecológica da vegetação neotropical. Salvador: Projeto RADAMBRASIL, 1982. 80 p. (Boletim Técnico, Ser. Vegetação, v. 1). 